\title{
CONSTRUCTION AND EVALUATION OF AN EDWARDSIELLA ICTALURI VIRULENCE PROTEIN F MUTANT
}

\author{
Safak Kalindamar, Hossam Abdelhamed, Hasan C. Tekedar, Attila Karsi*. \\ Department of Basic Sciences, College of Veterinary Medicine, Mississippi State University, Mississippi \\ State, MS, 39762
}

Edwardsiella ictaluri is a Gram-negative facultative intracellular pathogen causing enteric septicemia of catfish (ESC), a devastating disease causing millions of dollars production losses and treatment costs. $E$. ictaluri has variety of distinct mechanisms to survive in the stressful host environment. Type VI Secretion System (T6SS) is involved in survival of intracellular bacteria inside the host immune cells. However, the role of T6SS in E. ictaluri virulence is not known yet. Thus, the purpose of this research was to understand the extent to which T6SS is involved in E. ictaluri virulence. To this aim, we generated an E. ictaluri T6SS

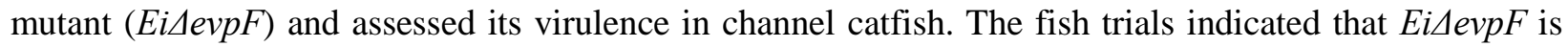

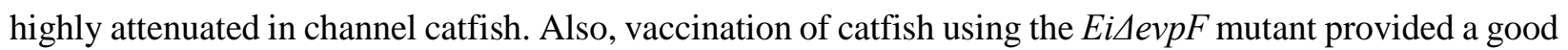
protection against wild-type E. ictaluri infection in catfish.

\author{
KEYWORDS: \\ Edwardsiella ictaluri \\ Enteric Septicemia of Catfish (ESC) \\ Type VI Secretion System \\ Live-attenuated vaccine \\ Virulence \\ *Corresponding author. Tel.: +1 6623250405 \\ E-mail address: karsi@cvm.msstate.edu.
}

